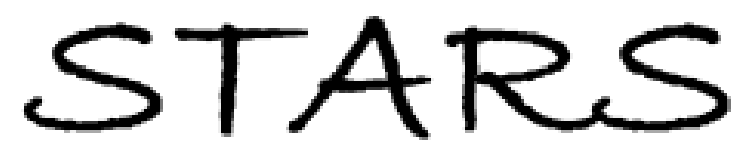

University of Central Florida

STARS

$1-1-2014$

\title{
International Immersion in Counselor Education: A Consensual Qualitative Research Investigation
}

\author{
Sejal M. Barden \\ University of Central Florida \\ Craig S. Cashwell
}

Find similar works at: https://stars.library.ucf.edu/facultybib2010 University of Central Florida Libraries http://library.ucf.edu

This Article is brought to you for free and open access by the Faculty Bibliography at STARS. It has been accepted for inclusion in Faculty Bibliography 2010 s by an authorized administrator of STARS. For more information, please contact STARS@ucf.edu.

\section{Recommended Citation}

Barden, Sejal M. and Cashwell, Craig S., "International Immersion in Counselor Education: A Consensual Qualitative Research Investigation" (2014). Faculty Bibliography 2010s. 5027.

https://stars.library.ucf.edu/facultybib2010/5027

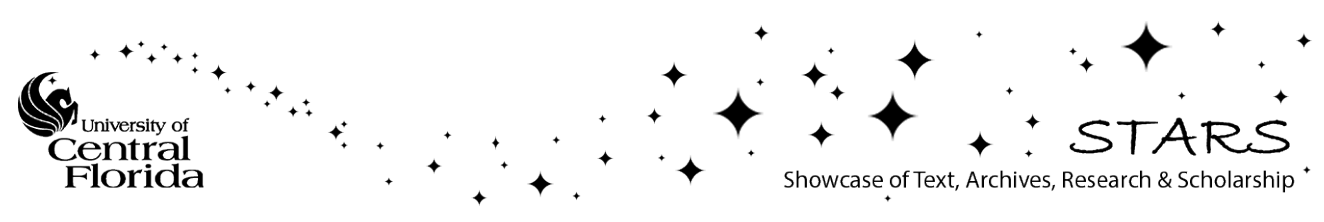




\title{
International Immersion in Counselor Education: A Consensual Qualitative Research Investigation
}

\begin{abstract}
Sejal M. Barden and Craig S. Cashwell
This study used consensual qualitative research methodology to examine the phenomenon of international immersion on counselor education students' $(N=10)$ development and growth. Seven domains emerged from the data (cultural knowledge, empathy, personal and professional impact, process/ reflection, relationships, personal characteristics, and structure). Implications for multicultural education and future research are discussed.
\end{abstract}

Keywords: consensual qualitative research, international immersion

\begin{abstract}
Este estudio empleó metodología consensuada de investigación cualitativa para examinar el fenómeno de la inmersión internacional en el desarrollo y crecimiento de estudiantes de educación en consejería $(N=10)$. Los datos arrojaron siete dominios (conocimiento cultural, empatía, impacto personal y profesional, proceso/reflexión, relaciones, características personales, y estructura). Se discuten las implicaciones para la educación multicultural y futuras investigaciones.
\end{abstract}

Palabras Clave: investigación cualitativa consensuada, inmersión internacional

The number of ethnic and racial minorities in the United States is increasing (Cordero \& Rodriguez, 2009; Leong \& Blustein, 2000). Specifically, racial and ethnic minorities compose one third of the total U.S. population (U.S. Census Bureau, 2008) with a trajectory that the United States will become majority-minority by 2042 , meaning that the majority of the population will be composed of ethnic and racial minorities. Because of the ethnic and cultural changes in the population, increased attention is being paid to the mental health care needs of diverse clients (Alexander, Kruczek, \& Ponterotto, 2005). Therefore, it is imperative for counselor preparation programs to train future counselors to work with clients from diverse backgrounds in culturally sensitive and competent ways (Alexander et al., 2005; DeRicco \& Sciarra, 2005; Ishii, Gilbride, \& Stensrud, 2009; Lindsey, 2005).

The counseling profession emphasizes diversity training in preparation standards (Council for Accreditation of Counseling and Related Educational Programs [CACREP], 2009) and cultural competence in ethical standards (American Counseling Association, 2005). Nevertheless, counselor preparation programs may not use the most effective pedagogical strategies to promote their students'

Sejal M. Barden, Department of Child, Family, and Community Sciences, University of Central Florida; Craig S. Cashwell, Department of Counseling and Educational Development, University of North Carolina at Greensboro. Correspondence concerning this article should be addressed to Sejal M. Barden, Department of Child, Family, and Community Sciences, College of Education and Human Performance, University of Central Florida, PO Box 161250, Orlando, FL 32816-1250 (e-mail: Sejal.Barden@ucf.edu). 
counseling competencies to provide services to clients from diverse backgrounds (Canfield, Low, \& Hovestadt, 2009; Coleman, 2006; DeRicco \& Sciarra, 2005). Traditional pedagogy in multicultural education primarily focuses on developing and increasing knowledge and skills for working with culturally diverse others. Although there is clear support for cultivating knowledge and skills, there is also a need for effective pedagogy to support a new level of infusion: pushing beyond the classroom walls and applying multicultural considerations to trainees' daily lives, and bridging classroom knowledge to real-world settings (Collins \& Pieterse, 2007). Therefore, inclusion of experiential pedagogies in counselor preparation programs that expose students to diverse worldviews and encourage cultural sensitivity may be warranted.

Students need educational experiences in which they encounter cultural dissonance, defined as learning processes that challenge cultural assumptions and facilitate affective, behavioral, and cognitive shifts that foster critical consciousness (Cordero \& Rodriguez, 2009; Weaver, 2005). Allport's (1954) contact hypothesis emphasizes that experiencing diversity through experiential methods that involve the person is more effective than using didactic methods of learning that primarily emphasize reading and talking. In addition, Allport's hypothesis suggests that cross-cultural contact may help reduce negative attitudes toward members from diverse backgrounds, providing a vehicle for the development of cultural competence (Diaz-Lazaro \& Cohen, 2001). Allport's hypothesis supports the need for divergent groups to be in prolonged contact with one another, highlighting support for cultural immersion experiences for helping professionals.

Cultural immersion provides participants an opportunity to interact with people from diverse backgrounds. Helping professionals (i.e., counselors, social workers, psychologists, nurses) can challenge their existing worldviews and assumptions, progressing along the continuum of intercultural sensitivity (Arthur \& Achenbach, 2002; DeRicco \& Sciarra, 2005; Diaz-Lazaro \& Cohen, 2001; Holcomb-McCoy \& Myers, 1999; Kim \& Lyons, 2003; Paige, Fry, Stallman, Josic, \& Jon, 2009). Immersion experiences, in which participants experience cultural dissonance while interacting with people from diverse backgrounds, may be an effective method for increasing helping professionals' cultural competence and core counseling skills (Canfield et al., 2009; Gilin \& Young, 2009). Specifically, cultural immersion experiences provide opportunities for students to connect with different cultures and rehearse adaptive functioning skills, promoting their intrapersonal development (e.g., self-awareness, selfefficacy, and critical consciousness; Arthur \& Achenbach, 2002; Cordero \& Rodriguez, 2009; DeRicco \& Sciarra, 2005; Diaz-Lazaro \& Cohen, 2001; Kim \& Lyons, 2003; Pedersen, 2010).

For example, Lindsey (2005) investigated the effect of an international immersion experience in Scotland for social work students. Enhanced selfawareness seemed to be a central theme for all participants. One student stated, "I have a new sense of clarity now, about myself, my needs and about other 
people as well. I feel stronger and more confident than I ever have in my life" (Lindsey, 2005, p. 237). Similarly, Cordero and Rodriguez (2009) qualitatively investigated the influence of a 12-day international immersion experience for social work graduate students in Puerto Rico. Results from qualitative journals indicated that participants reported increased self-awareness, cross-cultural knowledge, and commitment to social justice. Student reflections illustrated critical contemplation regarding their abilities and attitudes about working with people from diverse backgrounds. Cordero and Rodriguez stated that the transformative learning process of international immersion moved students from a simple desire to serve ethnic minorities to a deeper commitment to social action and human rights, including increased participation in lobbying efforts to advocate for the rights of Latinas/os.

Another example of interpersonal changes for participants of international immersion was illustrated in qualitative journal entries from graduate students in counseling, psychology, and education who participated in an immersion experience to South Africa (Tomlinson-Clarke \& Clarke, 2010). The majority of participants reported increases in cultural competence as a result of their participation in the immersion experience. Furthermore, pretrip reflections from students primarily focused on perceived cultural differences, reinforcing stereotypes and generalizations. Through ongoing, direct, cross-cultural contact, participants challenged their assumptions and stereotypes and began viewing cultural differences as less rigid, seeing parallels between the United States and South Africa. Participants' reflections also shifted in focus over the course of the trip, with later reflections focusing on integrating worldview and self: "I have a broader worldview and realize the depth and spectrum of experiences out there" and "I really saw the culture and lifestyle and began to understand the needs of people in a community" (Tomlinson-Clarke \& Clarke, 2010, p. 172). Similarly, Gilin and Young (2009) examined the effect of international immersion for 16 master's students in social work. Qualitative analysis of participants' reflection papers indicated that participants increased their awareness about social work policies and practices, discovered new ideas about social work, deepened their levels of empathy for people from backgrounds different from their own, and expanded and solidified their professional identity. In summary, literature on international immersion experiences highlights the changes in intrapersonal development for participants across helping profession disciplines.

Despite evidence suggesting positive developmental shifts for participants, however, researchers tend to focus on the short-term outcomes for immersion programs, with very few researchers examining the sustainability of change (Paige et al., 2009). One study (Norris \& Gillespie, 2008) conducted by the Institute for International Education of Students surveyed alumni from international study abroad programs from 1950 to 1999. Over 3,400 respondents participated in the survey, which assessed the long-term impact of the international experience on the participants' personal and professional lives. Over $95 \%$ of respondents stated that the international experience served as a 
catalyst for increased maturity and self-confidence and affected their worldview. Ninety-eight percent of respondents stated that the experience helped them better understand their cultural biases and values. Perhaps most important, however, almost all of the survey respondents (94\%) stated that the international experience continued to influence their interactions with people from diverse backgrounds, illustrating the sustainable impact of participation. In summary, researchers (Dwyer \& Peters, 2004) have examined the long-term effects of immersion experiences and found them to be impactful, but these long-term studies are not specific to counselors and counselor trainees. Other researchers (Alexander et al., 2005; Canfield et al., 2009; Crawford et al., 2004; Tomlinson-Clarke \& Clarke, 2010) have examined immersion experiences with counseling students, consistently finding gains from these experiences. To date, however, researchers who have examined the effect of immersion experiences on counseling students have considered only the immediate and relatively short-term personal and professional effects.

Considering the importance of multicultural counseling competence and potential effective pedagogy (international immersion) to promote counselor education students' development, the purpose of the study was to gain an understanding of the international immersion experience of counselor education students who were at least 1 year removed from their immersion experience to allow for an examination of the extended impacts of the immersion experience. The research question investigated was, What is the lived experience of counselor education students who participate in international immersion experiences?

\section{method}

This study was well suited for a qualitative approach given the exploratory nature of the investigation. We used consensual qualitative research $(\mathrm{CQR}$; Hill et al., 2005; Hill, Thompson, \& Williams, 1997) for our study. CQR highlights the use of multiple researchers, reaching consensus as a team, and the systematic methodology of examining the representativeness of results across cases. Hill et al. (1997) asserted that obtaining a strong sample of 8-15 participants is critical to effective CQR, given the emphasis of words and experiences in the CQR methodology.

\section{PARTICIPANTS}

Participants for the study $(N=10)$ were recruited to participate via purposive sampling. The purposive selection criteria included (a) all potential participants were engaged in a counseling-related international immersion experience within the last 1 to 5 years, (b) participants were enrolled in a CACREP-accredited counselor education program when they participated in the international immersion experience, and (c) participants were immersed in an international culture for a minimum of 10 days. All participants identified as White, with nine out of 10 participants identifying as female and 
one participant identifying as male. Participant ages ranged from 23 to 34 years, with an average of 27.9 years $(S D=3.41)$ at the time of interview. All participants had attended or were currently attending a CACREP-accredited counselor education program.

\section{PROCEDURE}

Approval to conduct the study was obtained from the university's institutional review board. Participants were recruited via e-mail; the first author contacted counselor educators who had facilitated an international immersion trip for counselor trainees within the last 5 years and requested their assistance in forwarding the study information on to immersion participants. The sample of immersion participants was selected based on meeting selection criteria and with the intent to include participants from varying immersion locations to yield diverse perspectives regarding the influence of immersion experiences on individuals. Four participants had immersed in South Africa and Botswana for 21 days, three participants had immersed in Bolivia for 12 days, and three participants had immersed in Guatemala for 12 days. In all cases, the immersion experiences were in international places that the participants had not previously visited.

Once participants were identified, we e-mailed to them a research packet that contained the informed consent, a demographic questionnaire, and a copy of the interview questions. After we received the signed informed consent and completed demographic form, an interviewer, who was not otherwise involved in the research study, scheduled and recorded telephone interviews using the semistructured interview questions as a guide. Interview questions were developed based on the empirical literature and research question of increasing understanding about how immersion influences counselor trainees. The questions were developed in a way that participant responses would confirm, challenge, or expand upon existing data regarding the experience of immersion and/or offer new information regarding the critical factors and sustained impact of the immersion experience. In addition, careful attention was paid to constructing the interview questions to minimize researcher bias and to elicit both positive and negative responses in an attempt to avoid response bias. Finally, the interview questions were piloted with a group of past participants of immersion who were asked to answer the questions and provide feedback regarding the clarity and sequence of questions, and minor adjustments were made to the questions to increase flow and make the questions more succinct and streamlined.

Considering that participants were geographically dispersed throughout the United States, all interviews were conducted via telephone. Telephone interviews tend to elicit fewer socially desirable responses compared to face-to-face interviews (Hill et al., 1997), which was considered particularly important given the somewhat sensitive nature of the content of the questions (e.g., multicultural empathy). Each interview was recorded us- 
ing a digital audio recorder. Participants were asked interview questions in a semistructured manner, with follow-up, probing, and/or clarification questions asked as needed. After all of the interviews were completed and transcribed, a four-member research team began the data analysis process using CQR methodology.

\section{DATA ANALYSIS}

Several key methodological components are central to the CQR data analysis process. CQR is based on the underlying assumption that multiple perspectives are more effective than singular perspectives when trying to understand complex issues and minimize researcher bias. Therefore, reaching consensus, which relies on mutual respect, equal involvement, and shared power, is integral to the process (Hill et al., 1997, 2005). To obtain multiple perspectives, CQR relies on a research team, which in this case included four members and one external auditor. All team members received training on the CQR method using the Hill et al. (1997) handbook and became familiar with the step-bystep process of CQR. Additionally, before collecting data, all team members participated in bracketing by recording their expectations and biases in an attempt to reduce avoidable subjectivity, alert individuals and team members about potential problems, and serve as a record to assess learning at the completion of the study, with new learning indicating that researchers were open to exploring the data and not just their own biases (Hill et al., 1997).

Team members were given research and interview questions and asked to look at the questions and write down their hunches, biases, or assumptions that may affect them when interpreting the data. For example, the first author shared her predilections of immersion experiences and told how she had been influenced by past immersions. Other team members shared varying experiences of international travel, although no other member had been on a counseling-related immersion experience. Team members expressed feeling that when participants immersed in cultures where they experienced differences in language, participants would feel an increased sense of being the "other" and, therefore, an increasing influence of immersion.

In this way, the research team members became familiar with their assumptions, which they kept in mind during the data coding process. As suggested by Hill et al. $(1997,2005)$, in addition to the research team recording and dialoguing about biases, an external auditor was used to increase objectivity and provide alternative perspectives that were not influenced by groupthink in the study. In summary, all of the strategies that Hill et al. (1997, 2005) emphasized, including the use of consensus, bracketing, and an external auditor to assist CQR researchers in increasing objectivity throughout the research process, were used.

Evaluating qualitative research for quality and trustworthiness is imperative given the subjective nature of the data. Hill et al. (1997) developed six criteria for evaluating qualitative research from a CQR perspective, with the first three criteria (trustworthiness of the method, coherence of the results, 
and representativeness of the results to the sample) viewed as required and the last three criteria (testimonial validity, applicability of results, and replication of the results across samples) viewed as recommended. For the purpose of this study, all of the required criteria and two of the three recommended criteria were used; only replication of the results across samples was not used. Accordingly, the results of this study can be strengthened with replications studies.

The first and most critical criterion, trustworthiness of the method, was attained by careful monitoring of both the data collection and data analysis process. In accordance with the recommendations from Hill et al. (2005), the interview consisted of 13 scripted questions, allowing for consistency across participants and adequate space and time for extensive probing. In addition to monitoring trustworthiness of the data collection methods, the research team was attentive to the composition of the sample, the consensus process within the research team (e.g., balance between members and appropriate disagreement), the appropriate use of an external auditor and use of auditor feedback, and consistency of rules across all cases (Hill et al., 2005). A heterogeneous sample was collected to explore similarities and differences between participant experiences and critical factors that may enable or block participants from experiencing sustainable transformation. In addition, participants were given the opportunity to review their raw transcript and provide feedback on data that had been transcribed. The second criterion, coherence of the results, highlights the importance of results and conclusions being logical, accounting for all data, and answering research questions. In the current study, triangulation, or the use of multiple sources for data collection and analyses, served to maintain coherence (Patton, 2002). Such use of the research team and reaching consensus is the cornerstone of CQR, allowing for multiple perspectives and reducing researcher bias (Hill et al., 2005; Patton, 2002). The third criterion, representativeness of the results to the sample, was maintained by the research team labeling each finding as general, typical, or variant. The fourth criterion, testimonial validity, or gathering input from participants, was done throughout the proposed study. Each participant received his or her raw transcript via e-mail and was asked to provide feedback on the accuracy of the transcribed interview; three out of 10 participants responded, stating that the transcripts accurately represented their interview. Applicability of results, or usefulness of findings, is another evaluative criterion. Results from the current study provide suggestions and implications for educators interested in mentoring students on international immersion experiences. Although the final criterion for evaluating the rigor of $\mathrm{CQR}$ methodology, replication of the results across samples, was not met in the current study, we believe that this study provides a foundation to inform future research on immersion experiences.

Hill et al. (1997) described three main steps to analyze data with CQR: (a) develop domains to cluster the data, (b) construct core ideas to summarize 
the main ideas expressed by participants, and (c) conduct a cross-analysis of data to identify categories that were consistent across participants. The suggested CQR data analysis process was followed as the research team discussed each domain, core idea, and consistent theme until consensus was reached. After completion of the domains and core ideas, an external auditor reviewed the results to ensure that the raw data were categorized correctly and that the core ideas were a relevant reflection of the data and used participants' words (Hill et al., 2005).

\section{results}

Data analysis yielded seven domains or topic areas that emerged from the data. As recommended by Hill et al. (1997, 2005), within each domain, the data were organized into categories. Eight categories were labeled as "general" findings (true for nine to 10 participants); 17 categories were labeled as "typical" findings (true for six to eight participants); and 45 categories were labeled "variant" findings (true for two to five participants). Discussion of the results is organized into the seven domains that emerged from the data: (a) cultural knowledge, (b) empathy, (c) personal and professional impact, (d) process/ reflection, (e) relationships, (f) personal characteristics, and (g) structure.

\section{CULTURAL KNOWLEDGE}

Participants stated that cultural knowledge, or the degree to which they understood cultural traditions, values, rituals, language, and food, was a result of two primary factors: observations and interactions within the immersion community. All 10 participants shared that observing cultural norms and patterns while immersed expanded their worldview and broadened the lens through which they see the world. For example, Participant 1 stated,

The immersion of being in their sites, working within the context of their culture, their beliefs, their systems, food, dress, the way things were handled, from the arrangement of rooms to the order to which people were supposed to eat and things like that. Being open and willing to accept that this is their style and I am the guest and to be part of that was eye opening to me.

In addition to observing cultural patterns, all 10 participants shared that interacting with community members while immersed influenced their cultural knowledge by educating and challenging their previously held stereotypes and assumptions and feeling connected to people around the world. Participant 8 stated,

I think just being a part of their culture and getting a feel for what their daily life was like. It helped me realize that the American way is not necessarily the "right" way, that our government, or even our social programs, all of these things that are so American, we might think that our way is the best way or the most beneficial way, but in Guatemala they had some services that were doing really well. It taught me to see that there is not one way, to be open to how the other cultures do it and different ways things can be done. 
Therefore, the cultural knowledge results suggested that participants not only were able to cognitively understand cultural differences, but also were able to effectively experience what life is like in other communities.

\section{EMPATHY}

For the purpose of this study, empathy is defined as the ability to enter a client's world (Rogers, 1961), to feel with the client rather than feel for the client (i.e., emotional/affective empathy; Capuzzi \& Gross, 1999), and to think with the client rather than for or about the client (i.e., cognitive empathy; Brammer, Abrego, \& Shostrom, 1993). Eight participants reported having shifts in their cognitive empathy, whereas six participants reported experiencing shifts in their emotional/affective empathy. Although fewer participants shifted in affective empathy when compared to cognitive empathy, the six participants who did shift and increase their affective empathy all shared that their own experience of being "other" is what enabled them to affectively experience what it may be like for marginalized clients whose daily experiences are that of being "other." Participants described struggling with the language barriers and trying to communicate their basic needs, possessing physical traits that were visibly different, and being affected by the large degrees of difference in cultural norms and patterns between their host country and home country. For example, Participant 9 stated,

I felt empathy towards the people there and being able to experience something completely different from my everyday life. Doing that and being in an area where English is not the dominant language, I developed a whole new understanding for immigrants living in the U.S.

Participant 5 shared how seeing the reality of people had an effect on her ability to empathize, stating, "To see where people come from, what is their reality . . . you read about that in a book, or a magazine, or see pictures, but there is nothing quite like being there in person." Another theme that emerged was that participants' empathy was also fostered through experiencing connections across cultures: feeling the "humanness" with people they could not speak to verbally but could still understand through universal messages and nonverbal language. Participant 1 stated that "using those human skills to build relationships such as listening, being empathic, gaining perspectives, helping people realize what they want and what they need and helping them get there" was a key takeaway from the experience.

\section{PERSONAL AND PROFESSIONAL IMPACT}

All 10 participants shared various ways in which they had been personally and professionally influenced by their immersion experience. In general, participants shared that participation in the immersion experience influ- 
enced their self-awareness, counselor self-efficacy, and worldview. All 10 participants shared how being immersed in a culture that was different from their own influenced their awareness of their own cultural norms and behaviors. For example, Participant 9 stated, "[The immersion] has helped me understand who I am as a person and different notions about my family. It forced me to take a look at my own personal situation and how we have different ideas and customs in my own family." The immersion experience highlighted participants' understanding that each person sees the world through his or her own lens. Participant 8 shared, "I feel like my knowledge of the world is greater and that my worldview is more wholesome as I experienced what life was like outside of the U.S." Similarly, Participant 3 stated, "Something that has really stuck with me is that when you are in another culture and you are immersed in another experience, you know your lens expands; the lens in which you see the world expands." Participant 5 shared, "Just opening your eyes to someone else's reality that is so different than your own, I think that automatically impacts your worldview. Just knowing that there are people out there that are living so differently than me."

Additionally, eight participants reported feeling gratitude, seven participants reported feeling affirmed in their career path, six participants expressed a desire to "pay it forward," and five participants expressed increased interest in leadership and social action initiatives. Participant 9 shared,

It has impacted my work in a profound manner . . . now I feel that I have the capacity to work with people from different cultures and I have the openness and desire to learn and understand that may not have developed otherwise [without participating in the immersion].

A result related to the sustained personal and professional influences of immersion is that all 10 participants reported some level of sustained change in their lives as a result of the immersion experience. Participant 5 shared that the changes may be less distinct because of time, but that the changes cannot be erased. She stated,

I don't think you can go back to being the same person you were before because the knowledge that I gained over there and the things I saw and experienced and noticed in myself and in my classmates . . you can't just erase it. Even if time maybe makes it less distinct, it just doesn't get erased.

Furthermore, when sharing about what meaning participants have made from their experience, eight participants shared that the experience was "very significant," and two participants shared that the experience was "significant" in their lives. Several participants commented on the immersion experience being an unforgettable experience, highlighted by one participant's expression, "I don't think you can ever get back to being the same person." 


\section{PROCESS/REFLECTION}

All 10 participants discussed engaging in some type of process/reflection activity while immersed internationally. The frequency, structure, and effectiveness of process/reflection activities varied considerably among participants, however, ranging from mandatory nightly process groups combined with journal writing to no formal process groups and nonmandated journaling. Typically, participants journaled and took part in large group discussions. Some participants discussed taking part in smaller, informal process discussions, and some shared that they processed through e-mailing and blogging with their support system back home.

Participants typically felt that interpersonal processing and reflecting was an effective method to obtain a deeper and richer experience while immersed. Participant 10 stated, "I would say every night, the group of students, we had processing time. Without that time, I know that the trip would not have been what it was for me ... it was a key highlight." Participant 3 shared how group reflection was helpful, stating,

We had a nightly process group, so every evening we would come together as a group and reflect as a group about our day, what was coming up for us, being in a different culture, what we loved, what were we struggling with, what were we thinking about and those kind of things. And X and Y [cultural hosts] participated in those groups. It created a space where we could be really honest with ourselves and we could be really honest with each other. I think it is essential to have that kind of space whenever you are in an immersion experience. It was essential to have that space to get out whatever you were feeling, whether it was joy or deep sadness, or frustration or whatever else. It not only helped us reflect on our experience but what was going on between us as group members.

Participant 7 shared a different experience of the group process, stating that the group was uncomfortable on many levels, but through that discomfort she was pushed to process on a deeper level than she would have without the group. She stated,

I think there was discomfort, but I think it is through discomfort that change happens, so it wasn't so uncomfortable that it ruined anything, maybe in some ways it has ignited more change if anything and more personal reflection. It helped me to look at myself and see myself as someone that impacts the group but also the group dynamics pushed me and forced me to look at myself in a deeper way than if I would have gone on the trip by myself or with just one other person. The group enhanced it, by causing discomfort and exciting change.

Although Participant 7 was able to work through power imbalances and discomfort, other participants described feeling judged and unable to process. For example, Participant 2 stated,

I always left feeling really bad about myself or bad for other group members. It just sort of felt that there was a lot of discourse in that process, a lot of finger pointing or blaming and I just didn't feel like it was a place where I felt like I could speak openly. I didn't feel like I could trust in the group to be able to process my experience. I think that not always is everyone ready to process and with the same amount of disclosure. I could see just sitting there, but you had to share and I didn't always feel comfortable with that. 
In addition to large group processing, participants discussed processing and reflecting on their experience through journaling. Three participants felt that journaling was effective in getting deeper in their experience, whereas three participants felt it was ineffective. Participants who felt journaling was helpful while immersed shared how the writing helped create a time and space for them to process their inner thoughts and feelings that they did not want to share with the group. Participant 10 shared,

It allowed me to think about things when there wasn't an opportunity to share with the group or I didn't want to share with the group. It was outlet or expression for more of my private thoughts that I was having.

Participant 3 shared how journaling enabled her to feel more connected to the culture and language as she switched from writing in English to writing in Spanish during the immersion experience. She stated,

In the beginning part of the trip I was writing in English. At some point I switched and started writing in Spanish, so it was good for as far as practicing the language and stuff. But it's also good to write in the language that you are surrounded by. It helped me to say personal things that were coming up for me on the trip, it helped to have a safe place to get them out ... a space to reflect on things, get them out and be honest with myself.

\section{RELATIONSHIPS}

Participants identified that relationships were at the cornerstone of the immersion experience. Under the domain of relationships, the results were divided into two categories: between-group interactions and within-group interactions. Typically, relationships in the between-group interactions (i.e., interactions between the immersion group and local community members) were reported as being the most positive critical incidents for participants. Seven participants described unexpected feelings of connections, positively sharing their experiences of overcoming language barriers and cultural differences and experiencing deep connections through universal experiences such as song, dance, and nonverbal communication. One participant shared, "I was amazed over and over even when there was a language barrier, it is not words you need, it is actions." Another participant spoke of being affected by the relationships that were established, stating,

I mean we are counselors, we are touched by people and that is what we find interesting. While it was great to see the historical sites and do some sightseeing, it's really the human components that stick with you ... really getting in there and spending time with people, that is what really gets to me.

On the other hand, relationships within the immersion group (e.g., interactions between facilitators and group members) were reported as being both the most positive and most negative critical incidents of the immersion. Participant 8 indicated feeling connected to group facilitators, stating, "The teachers from my college who facilitated the trip were great; I got to know one 
of them well and she continues to be a mentor to me. That was nice to have such a positive experience with someone I respect." Conversely, six participants shared that the interpersonal struggles they experienced with other group members and facilitators were unexpected and upsetting. Seven participants shared feeling excluded, isolated, and unsafe to discuss their experiences and challenges. Participant 5 shared how the group interactions did not meet her expectations, stating, "I knew a lot of group members before we went, so I kind of expected things to go one way and they didn't go as smoothly with group dynamics for me as I would have thought it would." Participant 2 shared how feeling excluded from the group colored her whole experience and left her feeling very isolated and homesick. She stated,

I thought that maybe I would not have had as many interpersonal problems with those I had traveled with, so in that regard, it did not meet my expectations. I felt isolated from the group a lot, I was homesick a lot when I was down there. I did not have the best relationship with some of the group members. As a whole, the group dynamics never sat well with me.

\section{PERSONAL CHARACTERISTICS}

Although participants were not specifically asked about how their own attitudes and personal characteristics influenced their immersion experience, several participants discussed how their ability to adapt, attitude while immersed, need for autonomy, feeling settled or unsettled in life, and being comfortable with the unknown affected them during immersion.

Participant 3 shared how she intentionally changes her mind-set when she travels, allowing herself to be open to the unknown and the challenges that she encounters. She stated, "When I travel and experience other cultures, this attitude or mind-set is imperative for me. I let go of the need to control, the need to know, and just experience and reflect. There is really nothing quite like it." Five participants shared how their own characteristics, such as the ability to be open and adaptable, as well as characteristics of group members, such as having a negative outlook and attitudes, affected their overall experiences. Participants also discussed how being settled in their life before the immersion was helpful, whereas one participant shared how not feeling settled in her personal life contributed to her negative experiences about the immersion. She stated, "I don't know if I was necessarily in a good place in my own life. I felt isolated from the group a lot, I was homesick a lot when I was down there." When asked what she would change about her experience, she stated, "I would go in with more of an open mind and take into account where I am in my own life before I was to go on an experience like that."

\section{STRUCTURE}

The results identified large variations in participants' needs and expectations related to the structure of the immersion experience. All 10 participants shared 
that being immersed in a culture that was different from their own culture was a positive component of the trip. Participant 5 shared,

I have never been to a purely Spanish-speaking country surrounded by Spanish people and so that was a big part of the appeal of going on the trip and experiencing the culture; it was the most critical part of the trip.

Six participants shared that overcoming language barriers and connecting through nonverbal language was helpful, whereas four participants shared that the language barrier hindered their ability to feel fully immersed and connected with the local culture. Participants also shared different perspectives on having free time versus structured time, with five participants sharing that they enjoyed having time that was not planned or structured, because it allowed them to explore the culture on their own and decompress. Participant 4 stated, "We stuck to whatever we needed to do that day, but the rest of the time was unplanned, so we were basically able to do what we wanted and I thought that was a huge benefit." Similarly, Participant 8 shared, "It was nice to have some alone time as I am an individual processor, so to walk around alone or behind the group, was nice to process on my own what we had done that morning or that night."

On the other hand, four participants reported that there were not enough structured interactions with community members and they would have appreciated more planned interactions. Five participants shared that the size of the group was too large, although one participant shared she felt a sense of safety partially attributed to the large size of her group. Participants also shared differing thoughts on the helpfulness of participating in pretrip planning meetings. Three participants shared that it was helpful to learn more about the culture in which they were going to be immersed. Participant 4 stated, "I think the pretrip planning of what we did before was helpful in preparing us for what we were going to experience." Similarly, Participant 6 stated, "We had some good training about the culture before we left." On the other hand, two participants stated that planning and preparation was ineffective in increasing their cultural knowledge. Participant 9 stated, "What I would have preferred to have less of was giving us too much information about the culture before we got to experience it for ourselves." These findings support the complexities and challenges instructors encounter when planning an international immersion course. The results underscored that instructors need to take the needs and expectations of their group into consideration when structuring the immersion course.

\section{limitations}

These results offer insight into the sustained influence of the international immersion experience of counselor education students. Nevertheless, the results need to be interpreted within the context of study limitations. Limitations of this study include sampling, research design, and researcher bias. For one, 
the large number of variant categories (45) and the relatively small number of general categories (eight) suggest that there are many idiosyncrasies in participants' experiences and that additional research is needed to tease out the nuances of participants' experiences.

The sample presented another limitation. Given the research methodology and inclusion criteria for participants, the purposive convenience sample was relatively small $(N=10)$ and lacked diversity. Because of the voluntary nature of participation and the nonrandom nature of the sampling procedure, participants may have had different characteristics from those who did not participate, which could have biased results. Furthermore, considering that all participants were volunteers and responding to issues such as cultural sensitivity, social desirability is a potential limitation. Scholars (e.g., Constantine \& Ladany, 2000) note that socially desirability, or the pattern of responding that reflects some individuals' need to provide perceived socially acceptable responses to questions rather than report their actual attitudes and feelings to present a favorable image, is a potential limitation in all self-report multicultural research. Another limitation of this study is researcher bias. Although several procedures were included to reduce researcher bias (i.e., independent interviewer, use of research team, bracketing exercise), the first author had numerous international immersion experiences, which may have contributed some bias to the study. Finally, the diversity in international experiences may be a limitation, because the immersion experiences were set up differently from one another. All participants had other experiences of traveling internationally either before the immersion, after the immersion, or both, possibly influencing their responses.

\section{implications for counselors and counselor educators}

Findings from this study have several implications for counselors and counselor educators. For one, researchers (e.g., Arthur \& Achenbach, 2002; D’Andrea \& Daniels, 2001; Holcomb-McCoy \& Myers, 1999) have indicated that counseling graduates feel ineffective and unprepared to work with clients from culturally diverse backgrounds as a result of insufficient training and preparation. However, results from this study support and extend previous research (e.g., Arthur \& Achenbach, 2002; DeRicco \& Sciarra, 2005; Diaz-Lazaro \& Cohen, 2001) on the influence of cultural immersion on counselor trainee development. Specifically, results from this study highlight the influence of international immersion on increasing empathy, self-awareness, and cultural sensitivity and on expanding worldviews. Furthermore, results from the current investigation support the sustainability of changes in counselor trainee development because of participation in an immersion. 
Implications from the current study also help to inform immersion facilitators and multicultural educators on influential factors that contributed to or impeded development for counselor trainees. For example, results from this study suggest that, when participants were out of their comfort zone, they experienced some form of cognitive and cultural dissonance, which contributed to shifting their worldviews and cultural schemas. Researchers (e.g., Allan, 2002; Arthur \& Achenbach, 2002) support cultural dissonance as being an essential experience for increasing cultural awareness and sensitivity. Therefore, for students who have majority statuses and limited opportunities of outsider experiences, immersion experiences may provide opportunities to not only increase cultural sensitivity and awareness, but also expand worldviews as students become aware of their previously unrecognized values and beliefs. Additionally, participants shared that increases in their ability to empathize were primarily attributed to observing and understanding cultural norms, experiencing what it is like to have the experience of being an outsider, and feeling connected across cultures while immersed. Educators may consider developing instructional strategies that replicate the experiences of being immersed in a culture in which students witness cultural norms that are different from their own and have the experiences of being the other. Creating experiential activities in which students enter a community in which they are the other and engage with diverse persons for extended periods may provide an opportunity for students to experience what it is like to be outside of the majority population, which will serve as a stepping-stone toward developing cultural empathy.

Last, participants in the current study typically reported the most positive critical incident of the immersion to be the relationships they formed with community members. Participants discussed that although visiting cultural sites and engaging in tourist activities were enjoyable, the most salient memory of the immersion was feeling connected to local community members. These findings are consistent with previous research indicating that students value direct interactions with people from diverse backgrounds, providing additional support for experiential multicultural pedagogy (Coleman, 2006; Heppner \& O’Brien, 1994; Tomlinson-Clarke, 2000).

In summary, researchers (e.g., Alexander et al., 2005; Canfield et al., 2009; Crawford et al., 2004; Tomlinson-Clarke \& Clarke, 2010) have consistently found positive benefits of immersion experiences in developing helping professionals, but have primarily evaluated only the immediate and relatively short-term personal and professional impacts. Results from this current study fill a gap in the literature and provide support for the sustained influence of immersion experiences on counselor development over time. As the frequency of participation in immersion experiences increases, it is necessary to document and evaluate both short- and longterm outcomes, coupled with critical factors that lead to sustained change among participants, including greater empathy for cultural differences, 
increased self-awareness of one's own biases and assumptions, and increased self-efficacy for working with clients from diverse backgrounds (Tomlinson-Clarke \& Wang, 1999).

\section{suggestions for future research}

This study provided an initial empirical exploration of the sustained impact of international immersion on counselors-in-training. In light of the aforementioned limitations, additional research is warranted to further understand the effect of international immersion on counselor development. Results from the current study suggest that counselor trainees who participated in an international immersion experienced varying degrees of sustained change, both personally and professionally. Individual differences that emerged from the data illustrate the complexity of planning, attending, implementing, and processing an international immersion experience for students and facilitators. There is a need for future researchers to include larger, more diverse samples to replicate and extend these findings.

Although this study illustrated that group dynamics influenced participants and hindered connections because of a lack of safety in the group, further research is needed in this area. More specifically, researchers need to investigate how to create group cohesion while also challenging student biases and assumptions.

Last, considering that the majority of research on the impact of immersion experiences has been qualitative, this body of literature would greatly benefit from mixed methods or quantitative research designs. For example, a pretestposttest experimental design would increase understanding of the changes attributed to the immersion experience. Furthermore, by integrating mixed methods or quantitative components with immersion and its relationship to counselor development, researchers may increase the generalizability of the results. In addition, a longitudinal design to assess the impact of immersion experiences would provide valuable information on both the short- and longterm impact of immersion.

\section{conclusion}

In summary, rapidly changing demographic shifts in the United States highlight the need for counselors to be well prepared in working with clients from diverse backgrounds (Tomlinson-Clarke \& Clarke, 2010; U.S. Census Bureau, 2008). Researchers (e.g., Arthur \& Achenbach, 2002; Coleman, 2006; Heppner \& O’Brien, 1994; Kim \& Lyons, 2003) emphasize that experiential pedagogical approaches enhance the effectiveness of multicultural counselor training beyond the traditional approach. The current study provides ample ground for further investigation on the influence and sustainability of change among immersion experiences for counselor trainees. 


\section{references}

Alexander, C. M., Kruczek, T., \& Ponterotto, J. G. (2005). Building multicultural competencies in school counselor trainees: An international immersion experience. Counselor Education and Supervision, 44, 255-266.

Allan, M. (2002). Cultural borderlands: Cultural dissonance in the international school. International Schools Journal, 21, 42-53.

Allport, G. W. (1954). The nature of prejudice. Oxford, England: Addison-Wesley.

American Counseling Association. (2005). ACA code of ethics. Alexandria, VA: Author.

Arthur, N., \& Achenbach, K. (2002). Developing multicultural counseling competencies through experiential learning. Counselor Education and Supervision, 42, 2-14.

Brammer, L. M., Abrego, P. J., \& Shostrom, E. L.(1993). Therapeutic counseling and psychotherapy (6th ed.). Englewood Cliffs, NJ: Prentice Hall.

Canfield, B. S., Low, L., \& Hovestadt, A. (2009). Cultural immersion as a learning method for expanding intercultural competencies. Family Journal, 17, 318-322.

Capuzzi, D., \& Gross, D. R. (1999). Counseling and psychotherapy: Theories and interventions (2nd ed.). Upper Saddle River, NJ: Merrill.

Coleman, M. N. (2006). Critical incidents in multicultural training: An examination of student experiences. Journal of Multicultural Counseling and Development, 34, 168-182.

Collins, N. M., \& Pieterse, A. L. (2007). Critical incident analysis based training: An approach for developing active racial/cultural awareness. Journal of Counseling E Development, 85, 14-23.

Constantine, M. G., \& Ladany, N. (2000). Self-report multicultural counseling competence scales: Their relation to social desirability attitudes and multicultural case conceptualization ability. Journal of Counseling Psychology, 47, 155-164.

Cordero, A., \& Rodriguez, L. N. (2009). Fostering cross-cultural learning and advocacy for social justice through an immersion experience in Puerto Rico. Journal of Teaching in Social Work, 29, 134-152.

Council for Accreditation of Counseling and Related Educational Programs. (2009). 2009 CACREP accreditation manual and application. Alexandria, VA: Author.

Crawford, P., Gosliner, W., Strode, P., Samuels, S., Burnett, C., Craypo, L., \& Yancey, A. (2004). Walking the talk: Fit WIC wellness programs improve self-efficacy in pediatric obesity prevention counseling. American Journal of Public Health, 94, 1480-1485.

D'Andrea, M., \& Daniels, J. (2001). Expanding our thinking about White racism: Facing the challenge of multicultural counseling in the 21 st century. In J. G. Ponterotto, J. M. Casas, L. A. Suzuki, \& C. M. Alexander (Eds.), Handbook of multicultural counseling (2nd ed., pp. 289-310). Newbury Park, CA: Sage.

DeRicco, J. N., \& Sciarra, D. T. (2005). The immersion experience in multicultural counselor training: Confronting covert racism. Journal of Multicultural Counseling and Development, 33, 2-16.

Diaz-Lazaro, C. M., \& Cohen, B. B. (2001). Cross-cultural contact in counseling training. Journal of Multicultural Counseling and Development, 29, 41-56.

Dwyer, M., \& Peters, C. (2004). The benefits of study abroad. Transitions Abroad, 27, 56-57.

Gilin, B., \& Young, T. (2009). Educational benefits of international experiential learning in an MSW program. International Social Work, 52, 36-47.

Heppner, M. J., \& O'Brien, K. M. (1994). Multicultural counselor training: Students' perceptions of helpful and hindering events. Counselor Education and Supervision, 34, 4-18.

Hill, C. E., Knox, S., Thompson, B. J., Williams, E. N., Hess, S. A., \& Ladany, N. (2005). Consensual qualitative research: An update. Journal of Counseling Psychology, 52, 196-205.

Hill, C. E., Thompson, B. J., \& Williams, E. N. (1997). A guide to conducting consensual qualitative research. The Counseling Psychologist, 25, 517-572.

Holcomb-McCoy, C. C., \& Myers, J. E. (1999). Multicultural competence and counselor training: A national survey. Journal of Counseling E Development, 77, 294-302.

Ishii, H., Gilbride, D. D., \& Stensrud, R. (2009). Students' internal reactions to a one-week cultural immersion trip: A qualitative analysis of student journals. Journal of Multicultural Counseling and Development, 37, 15-27.

Kim, B. S. K., \& Lyons, H. Z. (2003). Experiential activities and multicultural counseling competence training. Journal of Counseling E Development, 81, 400-408.

Leong, F. T. L., \& Blustein, D. L. (2000). Toward a global vision of counseling psychology. The Counseling Psychologist, 28, 5-9. 
Lindsey, E. W. (2005). Study abroad and values development in social work students. Journal of Social Work Education, 41, 229-249.

Norris, E. M., \& Gillespie, J. (2008). How study abroad shapes global careers: Evidence from the United States. Journal of Studies in International Education, 13, 382-397.

Paige, R. M., Fry, G. W., Stallman, E. M., Josic, J., \& Jon, J. E. (2009). Study abroad for global engagement: The long-term impact of mobility experiences. Intercultural Education, 20, 29-44.

Patton, M. Q. (2002). Qualitative research and evaluation methods. Thousand Oaks, CA: Sage.

Pedersen, P. J. (2010). Assessing intercultural effectiveness outcomes in a year-long study abroad program. International Journal of Intercultural Relations, 34, 70-80.

Rogers, C. R. (1961). On becoming a person: A therapist's view of psychotherapy. Boston, MA: Houghton Mifflin.

Tomlinson-Clarke, S. (2000). Assessing outcomes in a multicultural training course: A qualitative study. Counselling Psychology Quarterly, 13, 221-231.

Tomlinson-Clarke, S., \& Clarke, D. (2010). Culturally focused community-centered service learning: An international cultural immersion experience. Journal of Multicultural Counseling and Development, 38, 166-175.

Tomlinson-Clarke, S., \& Wang, V. O. (1999) A paradigm for racial-cultural training in the development of counselor competencies. In M. S. Kiselica (Ed.), Confronting prejudice and racism during multicultural training (pp. 155-167). Alexandria, VA: American Counseling Association.

U.S. Census Bureau. (2008). Statistical abstract of the United States. Washington, DC: Author.

Weaver, H. N. (2005). Explorations in cultural competence: Journeys to the four directions. Belmont, CA: Thomson Brooks/Cole. 